\title{
Anemia and Blood Transfusion in Subarachnoid Hemorrhage
}

\author{
Monisha Kumar, MD \\ Department of Neurology, Thomas Jefferson University, Philadelphia, PA
}

\section{Anemia in Subarachnoid Hemorrhage}

Anemia is a common problem among critically ill patients. Nearly two thirds of patients are anemic on admission to the intensive care unit (ICU) ${ }^{1}$ and between $70-95 \%$ of patients develop anemia by day $3 .{ }^{2,3}$ Lower hemoglobin levels decrease the oxygen carrying capacity of blood and may reduce tissue oxygenation. This is particularly detrimental for patients with subarachnoid hemorrhage $(\mathrm{SAH})$ as they are subject to increased metabolic demand for oxygen from cerebral ischemia.

The optimal hemoglobin concentration in patients with subarachnoid hemorrhage (SAH) is unknown. Thirty per cent of SAH patients have a hemoglobin $<10 \mathrm{~g} / \mathrm{dl}$ during hospitalization. ${ }^{4}$ Many patients are routinely hemodiluted as a part of hypertensive, hypervolemic, hemodilution (triple H) therapy. Hemodilution may improve blood rheology, but it has also been shown to impair brain tissue oxygenation and increase secondary brain injury. ${ }^{5}$

Patients with SAH are at risk for vasospasm and delayed ischemic deficits. Compromised oxygen carrying capacity could further predispose to ischemia. Anemia has been associated with increased ischemic deficits, but has not consistently been associated with development of vasospasm. ${ }^{6-9}$ One study demonstrated fewer ischemic events in subarachnoid hemorrhage patients with higher hemoglobin concentrations. ${ }^{7}$ Another study found that although transfusion significantly increased global cerebral oxygen delivery, it also resulted in reduced cerebral blood flow in areas affected by vasospasm. ${ }^{10}$ The decreased perfusion was thought to be mediated by increased viscosity.

In the uninjured brain, vasodilation of the cerebral arteries can compensate for decreased oxygen carrying capacity. Brain hypoxia is usually only manifest at hemoglobin concentrations less than $6 \mathrm{~g} / \mathrm{dl}^{11}$. When cerebral autoregulation is impaired, tissue hypoxia may occur at higher hemoglobin concentrations. However, the hemoglobin threshold below which cerebral metabolic dysfunction occurs remains unknown. One study sought to define this threshold in patients with high grade $\mathrm{SAH}$ (Hunt Hess grade IV or V) by measuring cerebral metabolism through the use of brain tissue oxygen tension monitoring (PbtO2) and lactate to pyruvate (LPR) measurements via cerebral microdialysis. ${ }^{9}$ Reduced PbtO2 levels and increased extracellular LPR are markers of cerebral metabolic dysregulation. They found that the incidence of brain hypoxia and cell energy dysfunction increased when hemoglobin levels were less than $9 \mathrm{~g} / \mathrm{dl}$ independent of other factors such as cerebral perfusion pressure and vasospasm. The authors concluded that maintenance of hemoglobin levels greater than $9 \mathrm{~g} / \mathrm{dl}$ may prevent secondary brain injury in poor-grade patients with $\mathrm{SAH}$.

Anemia is not only associated with increased ICU length of stay and increased risk of death in critically ill patients, but it also has been shown to be a predictor of poor outcome in SAH patients. ${ }^{1,8,12,13}$ Anemia is common in SAH, occurring in $36-39 \%$ of patients. ${ }^{8,13}$ One study of 580 SAH patients found that anemia was an independent predictor of death or severe disability at 90 days. ${ }^{13}$ Another study demonstrated that aneurysmal SAH patients with poor outcomes had lower daily hemoglobin levels. ${ }^{12}$

It is clear that anemia worsens outcome in subarachnoid hemorrhage, but it remains unclear whether blood transfusion to correct acute anemia is warranted. A meta-analysis of 4 concluded that in adult critically ill, trauma, and surgical patients, blood transfusion therapy was associated with increased morbidity and mortality. ${ }^{14}$

The treatment of anemia in the neurological ICU remains unclear in part because transfusion strategy trials have not included a significant number of neurologically critically ill patients. Some studies including patients with active cardiac ischemia have suggested benefit from a liberal transfusion approach $^{1,15}$; however, this has not been shown consistently. It is unclear whether results from these trials can be extrapolated to patients with cerebral ischemia. Neurological patients often require augmentation of cerebral blood flow to maintain perfusion and avoid ischemia.

Packed red blood cell (PRBC) transfusion has also been associated with increased cerebral vasospasm. In a retrospective study of $441 \mathrm{SAH}$ patients, post-operative PRBC transfusion was associated with an increased risk of both angiographic and symptomatic vasospasm.16 One of the postulated mechanisms suggested that transfused RBCs may be depleted of nitric oxide and therefore result in a blunted vasodilatory response to vasospasm.

Packed red blood cell transfusion increases blood viscosity. Increased blood viscosity coupled with increased oxygen carrying capacity may induce autoregulatory vasoconstriction, which would reduce, not augment, cerebral blood flow. A study of 8 anemic aneurysmal $\mathrm{SAH}$ patients who underwent pre- and posttransfusion PET scan evaluation, demonstrated a significant increase in oxygen delivery without compromising global cerebral blood flow. The rise in oxygen delivery was greater in regions of baseline oligemia, defined as areas of low oxygen delivery and a high oxygen extraction fraction. However, in territories of angiographic vasospasm, cerebral blood flow fell by 7 per cent. This was thought due to impaired autoregulation compounded by increase blood viscosity in blood vessels affected by vasospasm.

Concern about the safety of packed red blood cell transfusion, including immunosuppressive and microcirculatory complications, has led to a reappraisal of transfusion practices. The Transfusion Requirements in Critical Care (TRICC) trial was designed to determine whether a restrictive versus liberal transfusion strategy in the intensive care unit produced equivalent all cause mortality at 30 days and equivalent organ dysfunction. ${ }^{1}$ In this randomized controlled study, either a hemoglobin concentration of 7-9 g/dl or 10-12 g/dl was targeted as a trigger for transfusion. The in-hospital mortality rate was lower in the restrictive transfusion group, although the primary endpoint of 30-day mortality was not significantly different between the two groups. The authors recom- 
mended that critically ill patients receive PRBC transfusion when the hemoglobin concentration falls below $7 \mathrm{~g} / \mathrm{dl}$ and that hemoglobin levels be maintained between $7-9 \mathrm{~g} / \mathrm{dl}$.

Infectious complications of blood transfusion also limit its utility. Ameta-analysis of 9 observational studies concluded that among transfused adult critically ill, trauma, and surgical patients, the pooled odds ratio for infection was 1.88 (CI 1.52 - 2.24). ${ }^{14}$ Seventeen of eighteen studies included in that meta-analysis demonstrated that RBC transfusion was an independent predictor of death. In a study of trauma patients, transfusion of more than four units of blood increased the risk of peri-operative infection by a factor of 9.28. ${ }^{17}$ Ninety-two per cent of infections occurred in anemic patients and the rate of post-operative infections correlated with decreasing hemoglobin levels. Other studies of trauma patients have determined that blood transfusion therapy is an independent predictor of the systemic inflammatory response syndrome $^{18}$, multi-organ dysfunction ${ }^{19}$, increased nosocomial infections ${ }^{20}$ and mortality. ${ }^{21}$

The infectious complications of transfusion are thought to occur in large part from white blood cells and inflammatory cytokines that are present in stored red blood cells preparations. Transfusion of RBCs has been shown to trigger neutrophil activation and the release of proinflammatory cytokines. ${ }^{22}$ These factors may exacerbate the inflammatory changes known to be associated with vasospasm from aneurysmal SAH. Subarachnoid blood stimulates expression of cell adhesion molecules (CAMs) on the luminal surface of endothelial cells. ${ }^{23}$ Macrophages and neutrophils bind to the endothelial cells via these CAMs, and enter the subarachnoid space, where they phagocytose red blood cells. The macrophages and neutrophils die and degranulate two to four days after entering the subarachnoid space, releasing endothelins and oxygen free radicals which result in vasoconstriction.

Transfusion related acute lung injury (TRALI) is another significant complication of transfusion therapy that carries a mortality of 5 $-10 \%{ }^{24-30}$ It is the third most common cause of fatal transfusion reactions next to blood type incompatibility and hepatitis. ${ }^{31}$ TRALI is characterized by noncardiogenic pulmonary edema that develops during or soon after blood product transfusion. The signs and symptoms of TRALI are often mistaken for volume overload or pneumonia.

\section{Conclusion}

Anemia is common in subarachnoid hemorrhage and the optimal target hemoglobin in this disease remains unknown. Red blood cell transfusions in the intensive care unit are intended to augment oxygen delivery to tissues to improve tissue oxygenation. It is presumed that increased hemoglobin concentration increases oxygen carrying capacity and provides more oxygen to delivery-dependent tissue. However, whether blood transfusion successfully achieves improved tissue oxygenation remains unclear.

\section{References}

1. Hebert PC, Wells G, Tweeddale M, Martin C, Marshall J, Pham B, Blajchman M, Schweitzer I, Pagliarello G: Does transfusion practice affect mortality in critically ill patients? Transfusion Requirements in Critical Care (TRICC) Investigators and the Canadian Critical Care Trials Group. Am J Respir Crit Care Med 155:1618-1623, 1997.

2. Corwin HL: Blood transfusion in the critically ill patient. Dis Mon 45:409-426, 1999.

3. Groeger JS, Guntupalli KK, Strosberg M, Halpern N, Raphaely RC, Cerra F, Kaye W: Descriptive analysis of critical care units in the United States: patient characteristics and intensive care unit utilization. Crit Care Med 21:279-291, 1993.

4. Zauner A, Bullock R, Di X, Young HF: Brain oxygen, CO2, pH, and temperature monitoring: evaluation in the feline brain. Neurosurgery 37:1168-1176; discussion 1176-1167, 1995.

5. Hare GM, Mazer CD, Hutchison JS, McLaren AT, Liu E, Rassouli A, Ai J, Shaye RE, Lockwood JA, Hawkins CE, Sikich N, To K, Baker AJ: Severe hemodilutional anemia increases cerebral tissue injury following acute neurotrauma. J Appl Physiol 103:1021-1029, 2007.

6. Naidech AM, Jovanovic B, Wartenberg KE, Parra A, Ostapkovich N, Connolly ES, Mayer SA, Commichau C: Higher hemoglobin is associated with improved outcome after subarachnoid hemorrhage. Crit Care Med 35:23832389, 2007

7. Naidech AM, Kahn MJ, Soong W, Green D, Batjer HH Bleck TP: Packed Red Blood Cell Transfusion Causes Greater Hemoglobin Rise at a Lower Starting Hemoglobin in Patients with Subarachnoid Hemorrhage. Neurocrit Care, 2008.

8. Kramer AH, Gurka MJ, Nathan B, Dumont AS, Kassell NF, Bleck TP: Complications associated with anemia and blood transfusion in patients with aneurysmal subarachnoid hemorrhage. Crit Care Med 36:2070-2075, 2008.

9. Oddo M, Milby A, Chen I, Frangos S, MacMurtrie E, Maloney-Wilensky E, Stiefel M, Kofke WA, Levine JM, Le Roux PD: Hemoglobin concentration and cerebral metabolism in patients with aneurysmal subarachnoid hemorrhage. Stroke 40:1275-1281, 2009.

10. Dhar R, Zazulia AR, Videen TO, Zipfel GJ, Derdeyn CP, Diringer MN: Red blood cell transfusion increases cerebral oxygen delivery in anemic patients with subarachnoid hemorrhage. Stroke 40:3039-3044, 2009.

11. McLaren AT, Marsden PA, Mazer CD, Baker AJ, Stewart DJ, Tsui AK, Li X, Yucel Y, Robb M, Boyd SR, Liu E, Yu J, Hare GM: Increased expression of HIF-1alpha, nNOS, and VEGF in the cerebral cortex of anemic rats. Am J Physiol Regul Integr Comp Physiol 292:R403-414, 2007.

12. Kramer AH, Zygun DA, Bleck TP, Dumont AS, Kassell NF, Nathan B: Relationship between hemoglobin concentrations and outcomes across subgroups of patients with aneurysmal subarachnoid hemorrhage. Neurocrit Care 10:157-165, 2009.
13. Wartenberg KE, Schmidt JM, Claassen J, Temes RE, Frontera JA, Ostapkovich N, Parra A, Connolly ES, Mayer SA: Impact of medical complications on outcome after subarachnoid hemorrhage. Crit Care Med 34:617-623; quiz 624, 2006.

14. Marik PE, Corwin HL: Efficacy of red blood cell transfusion in the critically ill: a systematic review of the literature. Crit Care Med 36:2667-2674, 2008.

15. Carson JL, Duff A, Poses RM, Berlin JA, Spence RK, Trout R, Noveck H, Strom BL: Effect of anaemia and cardiovascular disease on surgical mortality and morbidity. Lancet 348:10551060, 1996.

16. Smith MI, Le Roux PD, Elliott JP, Winn HR: Blood transfusion and increased risk for vasospasm and poor outcome after subarachnoid hemorrhage. J Neurosurg 101:1-7, 2004.

17. Dunne JR, Malone D, Tracy JK, Gannon C, Napolitano LM: Perioperative anemia: an independent risk factor for infection, mortality, and resource utilization in surgery. J Surg Res 102:237-244, 2002

18. Dunne JR, Malone DL, Tracy JK, Napolitano LM: Allogenic blood transfusion in the first 24 hours after trauma is associated with increased systemic inflammatory response syndrome (SIRS) and death. Surg Infect (Larchmt) 5:395404, 2004.

19. Moore FA, Moore EE, Sauaia A: Blood transfusion. An independent risk factor for postinjury multiple organ failure. Arch Surg 132:620-624; discussion 624-625, 1997.

20. Claridge JA, Sawyer RG, Schulman AM, McLemore EC, Young JS: Blood transfusions correlate with infections in trauma patients in a dose-dependent manner. Am Surg 68:566-572, 2002.

21. Tornetta P, 3rd, Mostafavi H, Riina J, Turen C, Reimer B, Levine R, Behrens F, Geller J, Ritter C, Homel P: Morbidity and mortality in elderly trauma patients. J Trauma 46:702706, 1999.

22. Zallen G, Moore EE, Ciesla DJ, Brown M, Biffl WL, Silliman CC: Stored red blood cells selectively activate human neutrophils to release IL-8 and secretory PLA2. Shock 13:29-33, 2000.

23. Chaichana KL, Pradilla G, Huang J, Tamargo RJ: Role of inflammation (leukocyte-endothelial cell interactions) in vasospasm after subarachnoid hemorrhage. Surg Neurol, 2009.

24. Popovsky MA: Transfusion-related acute lung injury. Curr Opin Hematol 7:402-407, 2000.

25. Popovsky MA: Transfusion-related acute lung injury. Transfusion 35:180-181, 1995.

26. Popovsky MA, Chaplin HC, Jr., Moore SB: Transfusionrelated acute lung injury. Transfusion 33:444-445, 1993.

27. Popovsky MA, Chaplin HC, Jr., Moore SB: Transfusionrelated acute lung injury: a neglected, serious complication of hemotherapy. Transfusion 32:589-592, 1992.

28. Popovsky MA, Moore SB: Diagnostic and pathogenetic considerations in transfusion-related acute lung injury. Transfusion 25:573-577, 1985.

29. Shander A, Popovsky MA: Understanding the consequences of transfusion-related acute lung injury. Chest 128:598S 604S, 2005.

30. Silliman CC, Boshkov LK, Mehdizadehkashi Z, Elzi DJ, Dickey WO, Podlosky L, Clarke G, Ambruso DR: Transfusion-related acute lung injury: epidemiology and a prospective analysis of etiologic factors. Blood 101:454-462, 2003.

31. Sazama K: Reports of 355 transfusion-associated deaths: 1976 through 1985. Transfusion 30:583-590, 1990. 